\title{
Mechanisms of Gentamicin-Induced Dysfunction of Renal Cortical Mitochondria
}

\author{
II. Effects on Mitochondrial Monovalent Cation Transport
}

\author{
JOEL M. WEINBERG, PHILLIP G. HARDING, AND H. DAVID HUMES
}

Division of Nephrology, Department of Internal Medicine, University of Michigan, Ann Arbor, Michigan 48109

\author{
Received April 15, 1980
}

\begin{abstract}
Mitochondrial swelling techniques were used to evaluate the effects of the aminoglycoside antibiotic gentamicin on renal cortical mitochondrial monovalent cation permeability. Gentamicin behaved like EDTA to enhance energy-dependent $\mathrm{Na}^{+}$- and $\mathrm{K}^{+}$-acetate uptake with a relatively greater effect on $\mathrm{Na}^{+}$-acetate uptake. $\mathrm{Mg}^{2+}$ prevented and reversed the effects of both EDTA and gentamicin. Neither agent affected energy-independent uptake of $\mathrm{Na}^{+}$and $\mathrm{K}^{+}$-acetate. Gentamicin did not enhance energy-independent uptake of $\mathrm{K}^{+}$-and $\mathrm{Na}^{+}$-nitrate. Gentamicin enhanced energy-dependent swelling in a chloride- and phosphate-containing medium as a function of the medium $\mathrm{Na}^{+}$and $\mathrm{K}^{+}$concentration. This effect occurred simultaneously with gentamicin-induced stimulation of State 4 respiration and was blocked by $\mathbf{M g}^{2+}$. Gentamicin did not affect phosphate transport. The results are taken to indicate a specific action of gentamicin to enhance mitochondrial monovalent cation permeability at an $\mathbf{M g}^{2+}$ sensitive site and it is proposed that this accounts for the effects of gentamicin on mitochondrial respiration.
\end{abstract}

Acute in vitro exposure of normal renal cortical mitochondria to the aminoglycoside antibiotic, gentamicin, results in stimulation of State 4 respiration and inhibition of State 3 and DNP-uncoupled respiration. Both of these effects are (i) dependent on the presence of $\mathrm{Na}^{+}$and $\mathrm{K}^{+}$in the incubation medium, (ii) potentiated by the presence of a low concentration of EDTA, and (iii) prevented and reversed by $\mathbf{M g}^{2+}$ (1).

It has been observed, based on mitochondrial swelling studies, that gentamicin induces energy-dependent mitochondrial uptake of $\mathrm{KCl}$ and that this effect is inhibited by $\mathrm{Mg}^{2+}$ suggesting that gentamicin's effects on mitochondrial respiration could be mediated via alterations in $\mathrm{K}^{+}$transport (2). The companion paper demonstrated a major influence of $\mathrm{Na}^{+}$on the effects of gentamicin on mitochondrial respiratory parameters (1). If gentamicin's effects are indeed related to modification of the interaction of monovalent cations with the mitochondrial membrane at $\mathrm{Mg}^{2+}$-sensitive sites, it would be predicted that mitochondrial $\mathrm{Na}^{+}$transport, like $\mathrm{K}^{+}$transport, would also be affected by gentamicin and the system would be modulated by the presence of $\mathrm{Mg}^{2+}$ and EDTA.

The present studies were designed, using mitochondrial swelling as a measure of cation uptake $(3,4)$, to test this hypothesis and to better delineate the relationship between gentamicin-induced changes in mitochondrial monovalent cation transport and its effects on oxidative phosphorylation.

\section{METHODS}

Reagents, mitochondrial isolation procedures, and measurement of mitochondrial oxygen consumption were as previously described (1).

Mitochondrial swelling. Mitochondrial volume changes were followed as a function of the absorbance of the mitochondrial suspension measured at $546 \mathrm{~nm}$. Using this technique, mitochondrial swelling is accompanied by a decrease in absorbance by the suspension indicated by a downward deflection of the spectrophotometer trace $(3,4)$. Absorbance measurements were made using 1-ml curvettes in an Aminco-Chance DW-2 dual-wavelength spectrophotometer. A curvette containing incubation medium without mitochondria was used as reference. Rapid stirring of the mitochon- 


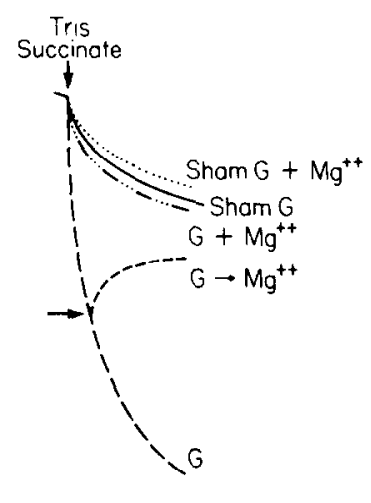

$\mathrm{Na}^{+}$Acetate

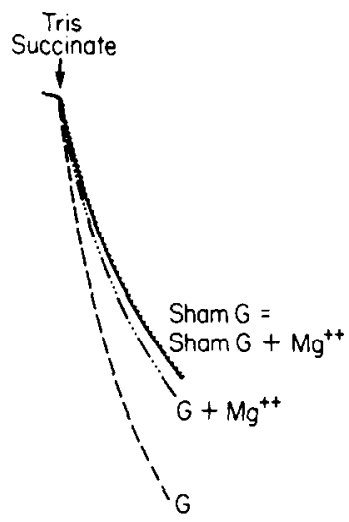

$\mathrm{K}^{+}$Acetate

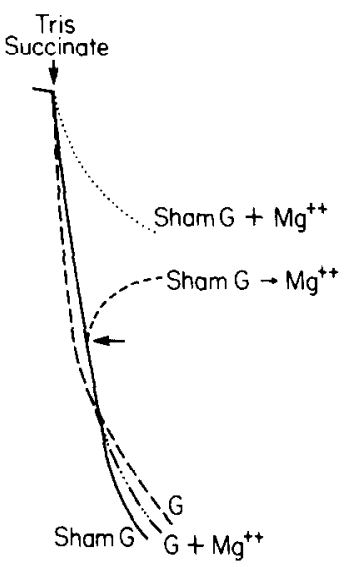

$\mathrm{Na}^{+}$Acetate EDTA

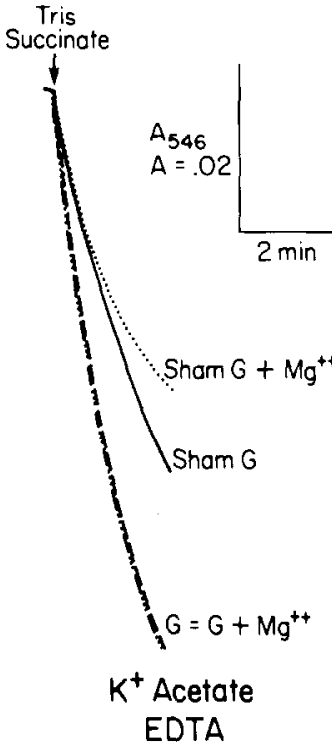

FIG. 1. Effects of gentamicin, EDTA, and $\mathrm{Mg}^{2+}$ on energy-dependent mitochondrial swelling in $\mathrm{Na}^{+}-$and $\mathrm{K}^{+}$-acetate. Renal cortical mitochondria $(0.9 \mathrm{mg}$ protein $/ \mathrm{ml}$ ) were suspended in a medium consisting of the indicated acetate salt ( $20 \mathrm{mM}), 100 \mathrm{mM}$ sucrose, $5 \mathrm{mM}$ Tris-acetate, $\mathrm{pH} 7.3,10^{-5} \mathrm{M}$ rotenone and, where indicated, $2 \mathrm{~mm}$ Tris-EDTA, pH 7.3. The experiment was started by adding $2 \mathrm{~mm}$ Tris - succinate, $\mathrm{pH}$ 7.3. In each medium, swelling was evaluated in the presence of $1 \mathrm{mM}$ gentamicin (G) and sham gentamicin (Sham $\mathrm{G}$ ), with and without $0.5 \mathrm{mM} \mathrm{Mg}^{2+}\left(\mathrm{Mg}^{2+}\right)$. These agents were present prior to the addition of Tris-succinate. The traces labeled $\mathrm{G} \rightarrow \mathrm{Mg}^{2+}$ and Sham $\mathrm{G} \rightarrow \mathrm{Mg}^{2+}$ show the affect of adding $\mathrm{Mg}^{2+}$ (at the points marked by arrows) while swelling was underway in the presence of gentamicin and sham gentamicin, respectively. Where tracings overlapped exactly, a single line is labeled with all conditions producing that line separated by $(=)$. drial suspension occurred when reagents were added in $10-\mu l$ volumes at the tip of a hooked glass stirring rod. Further experimental details are provided with the results.

For clarity of presentation, results are given in the form of actual tracings from typical experiments. Each of the reported studies was repeated on at least five or six separate mitochondrial preparations and all effects illustrated were unequivocally present in all preparations tested.

\section{RESULTS}

\section{(1) Swelling in Acetate Salts}

Renal cortical mitochondria exhibited swelling behavior in incubation media containing $20 \mathrm{mM}$ acetate $(\mathrm{Ac})^{1}$ salts and $100 \mathrm{mM}$ sucrose qualitatively similar to that which has been reported for heart mitochondria (5, 6) (Fig. 1). Major volume changes in the rotenone-treated mitochondria did not begin until substrate, $2 \mathrm{~mm}$ Tris-succinate, was added to the suspension. In the absence of EDTA, energy-dependent swelling in NaAc was minimal while substantially more swelling occurred in KAc. Adding $2 \mathrm{~mm}$ EDTA enhanced swelling markedly in $\mathrm{NaAc}$ and moderately in KAc. Preliminary experiments had shown that $0.1 \mathrm{mM}$ EDTA was substantially less potent in producing these effects. Five-tenths millimolar $\mathrm{Mg}^{2+}$ completely prevented the effects of EDTA when present before the initiation of swelling by the addition of substrate. Additional experiments showed that addition of $0.5 \mathrm{mM}$ $\mathrm{Mg}^{2+}$ after swelling in the presence of $\mathrm{NaAc}$ and EDTA was underway resulted in an immediate mitochondrial contraction.

Gentamicin produced energy-dependent mitochondrial volume changes qualitatively similar to those of EDTA in that swelling was enhanced in both NaAc and KAc and the relative effect in $\mathrm{NaAc}$ was much greater. $\mathrm{Mg}^{2+}(0.5 \mathrm{mM})$ completely prevented the effect of gentamicin and produced immediate contraction when added while gentamicin-induced swelling was already underway. In both $\mathrm{KAc}$ and NaAc, when $2 \mathrm{~mm}$ EDTA was present, the addi-

${ }^{1}$ Abbreviations used: EGTA, ethylene glycol bis $\beta$ aminoethyl ether) $N, N^{\prime}$-tetraacetate; EDTA, ethylenediaminetetracetate; DNP, 2,4-dinitrophenol; S3, State 3 ; S4, State 4; Ac, acetate; Tris, tris(hydroxymethyl)aminomethane. 


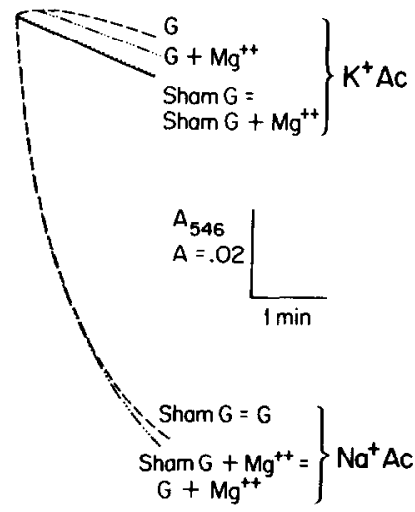

No EDTA

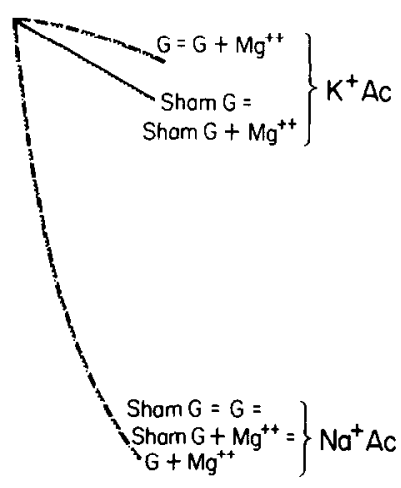

2 mM EDTA

FIG. 2. Effects of gentamicin, EDTA, and $\mathrm{Mg}^{2+}$ on energy-independent mitochondrial swelling in $\mathrm{Na}^{+}-$ and $\mathrm{K}^{+}$-acetate. The medium contained the test agent, the indicated acetate salt ( $\left.100 \mathrm{~mm}\right), 5 \mathrm{~mm}$ Trisacetate, $\mathrm{pH} 7.3,10^{-5} \mathrm{M}$ rotenone and, where indicated, $2 \mathrm{mM}$ Tris-EDTA, $\mathrm{pH}$ 7.3. Experiments were started by adding mitochondria $(0.9 \mathrm{mg}$ protein $/ \mathrm{ml})$. In each medium, swelling was evaluated in the presence of $1 \mathrm{mM}$ gentamicin (G), and sham gentamicin (Sham G), with and without $0.5 \mathrm{mM} \mathrm{Mg}^{2+}\left(\mathrm{Mg}^{2+}\right)$. These agents were present prior to the addition of Tris-succinate. Where tracings overlapped exactly, a single line is labeled with all conditions producing that line separated by $(=)$.

tional swelling increment induced by gentamicin was small and was not seen in all preparations. However, $0.5 \mathrm{mM} \mathrm{Mg}{ }^{2+}$ was no longer sufficient to block the enhanced swelling produced by the combination of EDTA and gentamicin. Five millimolar $\mathrm{Mg}^{2+}$ did completely block the enhanced swelling in the presence of both of these agents.

Renal cortical mitochondria suspended in incubation media containing $100 \mathrm{~mm}$ acetate salts behaved in a fashion similar to that previously reported for heart (5) and liver (7) mitochondria in that substantial energyindependent swelling occurred in $\mathrm{NaAc}$ but not in KAc (Fig. 2). Neither gentamicin nor EDTA enhanced these swelling responses.

\section{(2) Swelling in Nitrate Salts}

Unlike heart mitochondria (8), renal cortical mitochondria exhibited moderate swelling in $100 \mathrm{~mm} \mathrm{KNO}_{3}$ in the absence of an energy source (Fig. 3). Energy-independent swelling was markedly enhanced by the addition of valinomycin or $\mathrm{Hg}^{2+}$. Sham gentamicin, which consisted of $3 \mathrm{~mm}$ Tris-SO $\mathrm{S}_{4}, \mathrm{pH} 7.3$, produced a small transient increase in the rate of swelling. The addition of gentamicin did not enhance the baseline rate of swelling and did not interfere with the enhancement of swelling pro- duced by the subsequent addition of valinomycin. In $100 \mathrm{mM} \mathrm{NaNO}$, baseline energyindependent swelling was more rapid than that seen in $\mathrm{KNO}_{3}$. Gentamicin had no effect.

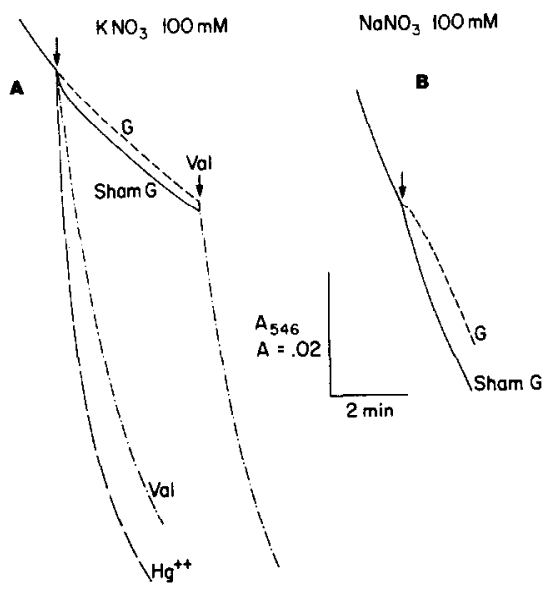

FIG. 3. Energy-independent swelling in nitrate salts. Renal cortical mitochondria $(0.9 \mathrm{mg}$ protein $/ \mathrm{ml})$ were suspended in a medium consisting of either $100 \mathrm{mM}$

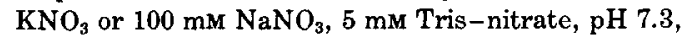
and $10^{-5} \mathrm{M}$ rotenone. Following a baseline period, the indicated agents were added at the point marked by the arrow. Agents tested were $1 \mathrm{mM}$ gentamicin (G), sham gentamicin (Sham G), $100 \mu \mathrm{g} / \mathrm{ml} \mathrm{HgCl}_{2},\left(\mathrm{Hg}^{2+}\right.$ ), and $2.5 \times 10^{-7} \mathrm{M}$ valinomycin (val). In the gentamicin experiment in $\mathrm{KNO}_{3}$, valinomycin was also added after gentamicin. 
$\mathrm{KCl} O \mathrm{mM} \quad \mathrm{KCl} 10 \mathrm{mM} \quad \mathrm{KCl} 75 \mathrm{mM} \quad \mathrm{KCl} 150 \mathrm{mM}$
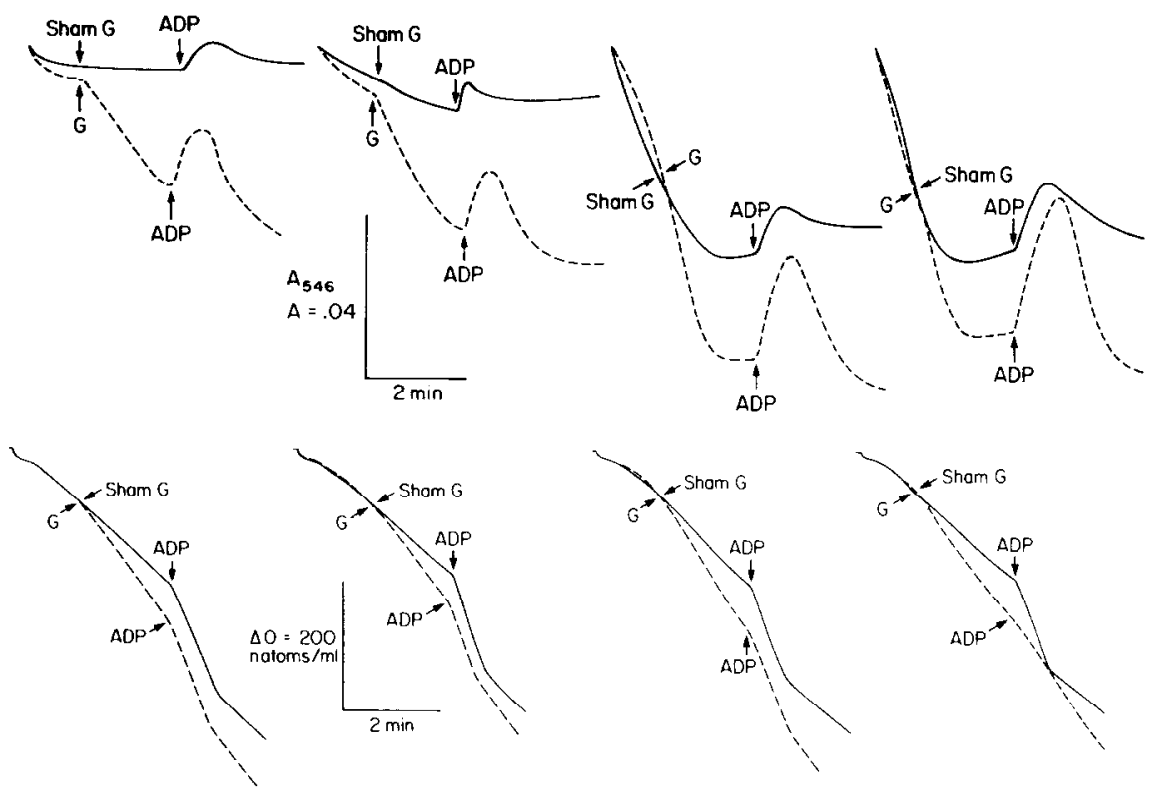

FIG. 4. Correlation of the effects of gentamicin on mitochondrial respiration and swelling. The top figures demonstrate the mitochondrial volume changes occurring in a series of incubation media containing $0,10,75$, and $150 \mathrm{mM} \mathrm{KCl}$. Every medium also contained sufficient sucrose, depending on the amount of $\mathrm{KCl}$, to maintain constant osmolarity, $10 \mathrm{~mm}$ Tris $-\mathrm{PO}_{4}, \mathrm{pH} 7.3,5 \mathrm{~mm}$ Tris $-\mathrm{HCl}, \mathrm{pH} 7.3,10^{-5} \mathrm{M}$ rotenone, $1 \mathrm{mM}$ EGTA, and $0.1 \mathrm{mM}$ EDTA. Each experiment was started by adding substrate, $10 \mathrm{mM} \mathrm{Na}{ }^{+}$succinate, to the suspension of mitochondria $(0.9 \mathrm{mg}$ protein $/ \mathrm{ml})$ in incubation medium. At $1 \mathrm{~min}$, either 1 $\mathrm{mM}$ gentamicin or sham gentamicin ( $3 \mathrm{mM}$ Tris $-\mathrm{SO}_{4}, \mathrm{pH} 7.3$ ) was added followed at $3 \mathrm{~min}$ by $0.4 \mu \mathrm{mol}$ ADP. The bottom figures demonstrate the oxygen consumption tracings obtained for the same preparation in parallel, simultaneously performed experiments. Mitochondrial suspensions were identical to the ones in the corresponding swelling experiments except mitochondrial protein $=0.65 \mathrm{mg} / \mathrm{ml}$. Gentamicin-treated preparations are indicated by (-- ) in both swelling and oxygen consumption studies.

(3) Swelling in the Incubation Media Used for Studies of Respiratory Parameters

In order to better correlate the effects of gentamicin on mitochondrial respiratory parameters which were detailed in the companion paper (1) with gentamicin-induced mitochondrial volume changes, mitochondrial swelling was studied in the same incubation media and under the same conditions used for those studies (Fig. 4).

Baseline energy-dependent swelling, in the absence of gentamicin, was enhanced as medium $\mathrm{KCl}$ concentration increased. At every $\mathrm{KCl}$ concentration tested, $1 \mathrm{mM}$ gentamicin immediately produced an additional swelling increment and, as can be seen from the companion oxygen consumption traces, this coincided with the stimulation of S4 respiration produced by gentamicin. When ADP was added to the sham gentamicin mitochondrial suspensions, immediate contraction occurred followed, upon exhaustion of the added ADP, by repeat swelling at a relatively slow rate. When gentamicin was present, the ADP-induced contractions were of larger amplitude than were seen in the sham gentamicin suspensions. Of note, if DNP was added to the mitochondrial suspensions in lieu of ADP, immediate contraction occurred and this was of greater amplitude in the presence of gentamicin. This contraction, however, was not followed by reswelling in either the gentamicin or sham gentamicin suspensions (Fig. 5).

If $\mathrm{Na}^{+}$was not present in the incubation medium, the amplitude of swelling induced 


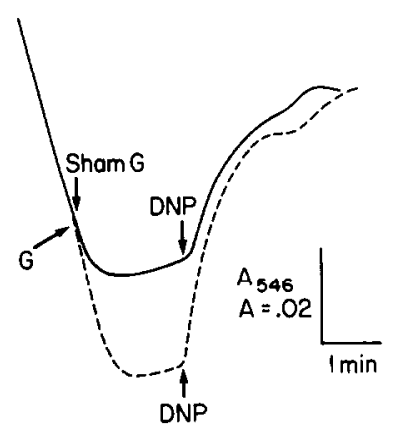

FIG. 5. Effects of DNP on mitochondrial swelling. The suspension consisted of mitochondria $(0.9 \mathrm{mg}$ protein/ml), $150 \mathrm{mM} \mathrm{KCl}, 10 \mathrm{mM}$ Tris- $\mathrm{PO}_{4}, \mathrm{pH} \mathrm{7.3,5} \mathrm{mM}$ Tris- $\mathrm{HCl}, \mathrm{pH} 7.3,10^{-5} \mathrm{M}$ rotenone, $1 \mathrm{mM}$ EGTA, and $0.1 \mathrm{mM}$ EDTA. The experiments were started with the addition of $10 \mathrm{mM} \mathrm{Na}{ }^{+}$-succinate. At 1 min either sham gentamicin or $1 \mathrm{mM}$ gentamicin (---) were adcied. At $2 \min 10^{-4} \mathrm{M}$ DNP was added.

by gentamicin was diminished (Fig. 6). In 0 $\mathrm{mM} \mathrm{KCl}$, gentamicin actually produced slight mitochondrial contraction while in $\mathbf{1 5 0}$ $\mathrm{mM} \mathrm{KCl}$ gentamicin induced an increase in swelling but to a lesser degree than when $\mathrm{Na}^{+}$was present.

If $0.5 \mathrm{mM} \mathrm{Mg}{ }^{2+}$ was added to the standard $150 \mathrm{mM} \mathrm{KCl} \mathrm{Na}{ }^{+}$-containing medium before the initiation of energy-dependent swelling, baseline swelling was diminished and gentamicin had no effect. If the $\mathrm{Mg}^{2+}$ was added after swelling was underway, an immediate contraction occurred, irrespective of the presence of gentamicin (Fig. 7). The oxygen consumption traces corresponding to these experiments are illustrated in Fig. 4 of the companion paper (1) and show that prevention or reversal of gentamicin's swelling effects coincided with similar alterations of gentamicin's effects on oxygen consumption.

\section{(4) Effects of Gentamicin on Phosphate Transport}

Because alterations in mitochondrial phosphate transport can effect mitochondrial cation transport properties, as demonstrated by the effects of mercurials (9), the effects of gentamicin on mitochondrial $\mathrm{P}_{i}$ transport were evaluated.

Renal cortical mitochondria exhibited energy-dependent swelling in $\mathrm{KH}_{2} \mathrm{PO}_{4}$ (Fig. 8). If $\mathrm{Hg}^{2+}$, a well-studied inhibitor of mito- chondrial $P_{i}$ transport (10), was present before the addition of substrate, this swelling was markedly inhibited. Adding $\mathrm{Hg}^{2+}$ while swelling was underway led to its immediate cessation. Gentamicin had no effect on swelling under these conditions whether present before or added after substrate.

Interference with mitochondrial phosphate transport leads to mitochondrial swelling in the presence of DNP and ATP due to blockage of exit from the mitochondria of $\mathrm{P}_{\mathrm{i}}$ derived from the hydrolysis of ATP (10). In the presence of $\mathrm{Hg}^{2+}$, renal cortical mitochondria exhibited spontaneous swelling prior to the addition of ATP, but the rate of swelling substantially accelerated upon addition of ATP and this effect was blocked by oligomycin (Fig. 9). In the presence of sham gentamicin or gentamicin only a small nonsustained increase in swelling was seen upon the addition of ATP indicating that no major block in $\mathrm{P}_{\mathrm{i}}$ transport was occurring under these conditions.

\section{DISCUSSION}

It has been well established that, under appropriate test conditions, light scattering

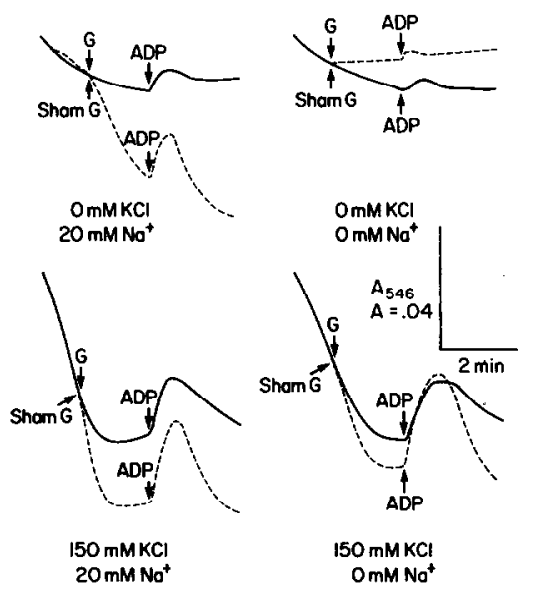

FIG. 6. Effect of $\mathrm{Na}^{+}$on degree of swelling produced by gentamicin. The experimental conditions were as outlined in Fig. 4 except that substrate consisted of either $10 \mathrm{mM} \mathrm{Na}^{+}$-succinate to produce a concentration of $20 \mathrm{mM} \mathrm{Na}{ }^{+}$or $10 \mathrm{mM}$ Tris-succinate where $0 \mathrm{mM}$ $\mathrm{Na}^{+}$was desired. Gentamicin-treated preparations are indicated by (---). In the $0 \mathrm{mM} \mathrm{KCl}$ suspensions, $\mathrm{KCl}$ was replaced by $300 \mathrm{mM}$ sucrose to maintain constant osmolarity. 


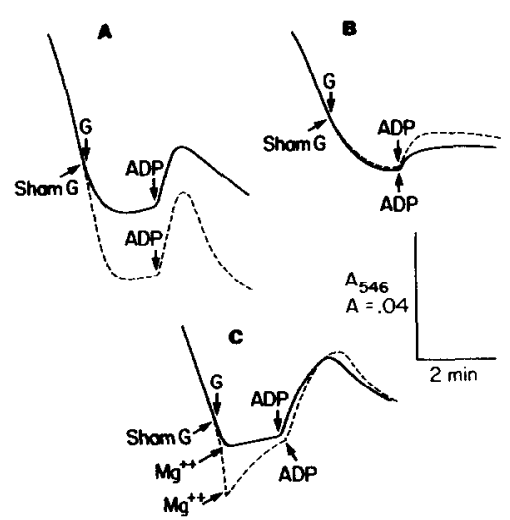

FIG. 7. Effects of $\mathrm{Mg}^{2+}$ on mitochondrial swelling. Experimental procedures were as described in Fig. 4 except that all incubation media contained $150 \mathrm{mM} \mathrm{KCl}$. Gentamicin-treated preparations are indicated by (-- ). (a) Swelling responses in the absence of $\mathrm{Mg}^{2+}$; (b) swelling response in the presence of $0.5 \mathrm{mM} \mathrm{Mg}^{2+}$; (c) effect of adding $0.5 \mathrm{mM} \mathrm{Mg}{ }^{2+}$ at indicated point after swelling was underway.

by mitochondrial suspensions is a function of mitochondrial volume and that mitochondria undergo osmotic volume changes depending on their permeability to available solutes $(3,4,11)$. Studies of mitochondrial swelling in conjunction with direct measurements of cation content have provided much information about the monovalent cation transport properties of the inner mitochondrial membrane (4). It has been proposed that mitochondrial monovalent cation transport is secondary to a combination of electrophoretic uniport and specific cation $/ \mathrm{H}^{+}$antiport components $(4,12)$. Although complete agreement regarding these mechanisms has not yet been reached (13-15), it is clear that a portion of membrane-bound $\mathrm{Mg}^{2+}$ plays an important role in limiting the transmembrane permeability of the inner mitochondrial membrane to monovalent cations, that $\mathrm{Na}^{+}$permeability is selectively limited by $\mathrm{Mg}^{2+}$ to a much greater extent than $\mathrm{K}^{+}$ permeability, and that these effects are most evident when mitochondria are in an energized state $(5,6,16,17)$. Heretofore, the $\mathrm{Mg}^{2+}$ chelating action of EDTA has been essential for demonstrating these properties.

'The data in this paper provide multiple lines of evidence that gentamicin acts specifically on this $\mathrm{Mg}^{2+}$-sensitive monovalent cation permeability pathway and that the results of this interaction account for most of gentamicin's effects on mitochondrial respiration.

(i) Like EDTA, gentamicin preferentially enhanced energy-dependent swelling in $\mathrm{NaAc}$ relative to KAc, the effects of both gentamicin and EDTA were completely blocked by $0.5 \mathrm{mM} \mathrm{Mg}^{2+}$, and their effects were additive as indicated by the failure of $0.5 \mathrm{mM} \mathrm{Mg}^{2+}$ to completely block enhanced swelling when both gentamicin and EDTA were present. In this circumstance, however, $5 \mathrm{mM} \mathrm{Mg}^{2+}$ completely blocked the enhanced swelling. The effects of both EDTA and gentamicin were also reversible by $\mathrm{Mg}^{2+}$. In contrast to these effects on energy-dependent cation uptake, neither gentamicin nor EDTA had any effect on the energy-independent uptake of $\mathrm{KAc}$ and NaAc.

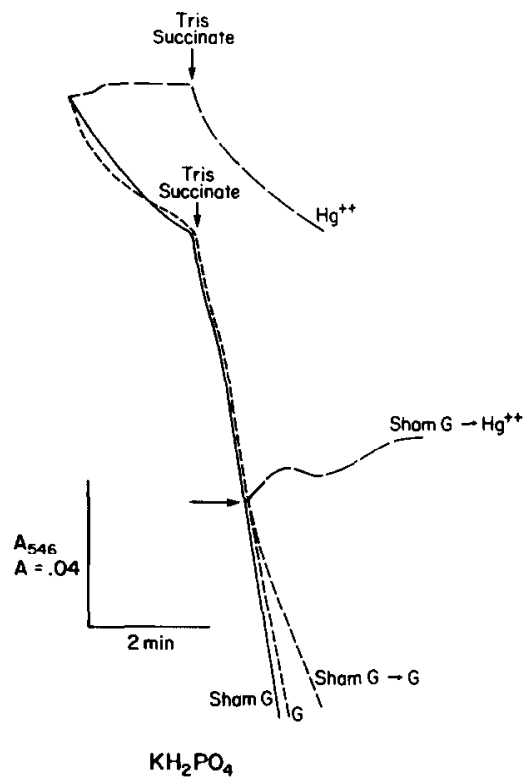

FIG. 8. Swelling behavior in $\mathrm{KH}_{2} \mathrm{PO}_{4}$. The suspension contained mitochondria $(0.7 \mathrm{mg}$ protein $/ \mathrm{ml}), 50 \mathrm{mM}$ $\mathrm{KH}_{2} \mathrm{PO}_{4}, 50 \mathrm{~mm}$ sucrose, $10 \mathrm{~mm}$ Tris $-\mathrm{PO}_{4}$, pH 7.3, $10^{-5} \mathrm{M}$ rotenone, and the indicated agent: sham gentamicin (Sham G), $1 \mathrm{mM}$ gentamicin (G), $100 \mu \mathrm{g} / \mathrm{ml} \mathrm{HgCl}_{2}$ $\left(\mathrm{Hg}^{2+}\right)$. Energy-dependent swelling was initiated by the addition of $10 \mathrm{~mm}$ Tris-succinate at the indicated point. The affects of adding $\mathrm{G}$ and $\mathrm{Hg}^{2+}$ after swelling was underway were also determined by adding them in separate experiments to the Sham G preparation at the indicated point. 
(ii) Unlike valinomycin and $\mathrm{Hg}^{2+}$, two other well-established modulators of mitochondrial cation permeability (4), gentamicin did not enhance energy-independent permeability to $\mathrm{K}^{+}$in the presence of nitrate. Gentamicin, additionally, had no effect on passive $\mathrm{Na}^{+}$permeability in the presence of $\mathrm{NO}_{3}^{-}$.

(iii) Gentamicin did not affect phosphate transport.

(iv) In the complex chloride- and phosphate-containing medium used for studying mitochondrial respiration, gentamicin enhanced swelling as a function of the concentrations of $\mathrm{Na}^{+}$and $\mathrm{K}^{+}$. These effects were completely prevented and reversed by $\mathrm{Mg}^{2+}$, and their time course suggested that the gentamicin-induced increases in energydependent cation transport could account for the increases in S4 respiratory rates produced by gentamicin. A volume correlate for the gentamicin-induced inhibition of S3 and DNP-uncoupled respiration was also noted. Inhibition of these respiratory states was associated with maximal swelling during the period preceding addition of $\mathrm{ADP}$ or DNP and maximal contraction upon addition of these agents. Whether the volume changes themselves induce membrane alterations responsible for the inhibition of $\mathrm{S} 3$ and DNP-uncoupled respiration or whether both the volume changes and the inhibitory effects are reflections of the same primary membrane effects of gentamicin remains unclear at this point.

The data presented in this paper and the companion paper (1), therefore, detail a highly specific and partly reversible action of gentamicin at the inner mitochondrial membrane to compete with $\mathrm{Mg}^{2+}$ (as was suggested by earlier work (2)) and, thereby, affect the interaction of monovalent cations with the mitochondrial membrane, in turn altering the efficacy of oxidative phosphorylation by diverting the energy of substrate oxidation to monovalent cation transport.

In view of this likely mechanism for gentamicin's action at the inner mitochondrial membrane, it is of note that the potency of other clinically relevant aminoglycoside antibiotics in producing both stimulation of S4 and inhibition of S3 and DNP-uncoupled respiration in renal cortical mitochondria

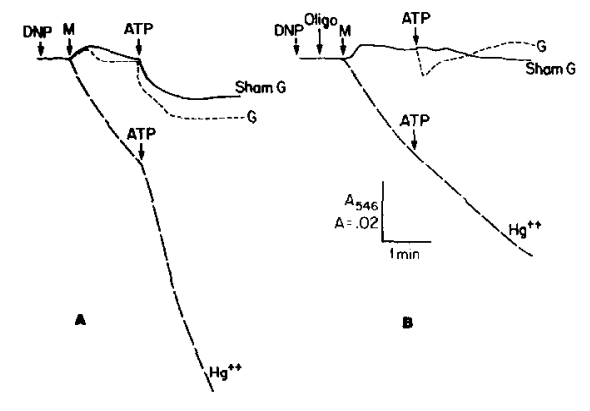

FIG. 9. Effect of gentamicin and $\mathrm{Hg}^{2+}$ on swelling induced by DNP and ATP. The suspensions contained mitochondria $(0.7 \mathrm{mg}$ protein $/ \mathrm{ml})$. Sucrose, $250 \mathrm{mM}$, $10 \mathrm{~mm}$ Tris- $\mathrm{HCl}, \mathrm{pH} 7.3,10^{-5} \mathrm{M}$ rotenone, $10^{-4} \mathrm{M} \mathrm{DNP}$, and the indicated test agent: sham gentamicin (Sham G) $1 \mathrm{~mm}$ gentamicin (G), or $100 \mu \mathrm{g} / \mathrm{ml} \mathrm{HgCl}_{2}\left(\mathrm{Hg}^{2+}\right)$. Mitochondria were added at M. ATP, $5 \mathrm{mM}$, was added at the indicated point. (A) Oligornycin not present; (B) oligomycin, $7 \mu \mathrm{g} / \mathrm{ml}$, present.

closely correlates with the degree to which they are cationic at physiologic $\mathrm{pH}$ (18). This likely influences their ability to compete with $\mathrm{Mg}^{2+}$ for membrane sites.

The ultimate effects of gentamicin on mitochondria in the complex intracellular milieu of the renal cortical tubular cell, its site of in vivo toxicity, are undoubtedly a function of multiple factors only some of which can be duplicated in vitro. Thus, $\mathrm{Mg}^{2+}$ is abundant intracellularly (19) and might be expected to limit the ability of gentamicin to interact with the mitochondrial membrane. However, in vivo exposure of mitochondria to gentamicin is constant for prolonged periods during treatment courses, a situation different from acute exposure in vitro, and this may mitigate some of the protective effect of $\mathrm{Mg}^{2+}$. In this regard, it is of interest that gentamicin produces $\mathrm{Mg}^{2+}$ depletion (20) which could, in turn, enhance its toxicity. It is of note that $\mathrm{K}^{+}$depletion enhances gentamicin nephrotoxicity (21).

However, given the difficulties in directly extrapolating from the in vitro to the in vivo situation, further studies will clearly be required to determine whether alterations in renal cortical mitochondrial function during gentamicin nephrotoxicity are related to interactions of the type detailed in this and the companion paper (1). 


\section{REFERENCES}

1. Weinberg, J. M., ANd Humes, H. D. (1980) Arch. Biochem. Biophys. 205, 222-231.

2. BENDIRDJIAN, J. P., FoUCHER, B., AND FILlaSTRE, J. P. (1978) in Nephrotoxicity: Interaction of Drugs With Membrane Systems, Mitochondria-Lysosomes (Fillastre, J. P., ed.), pp. 315332, Masson, New York.

3. Chappell, J. B., AND Crofts, A. R. (1966) in Regulation of Metabolic Processes in Mitochondria (Tager, J. M., Papa, S., Quagliariello, E., and Slater, E. C., eds.), pp. 293-316, Elsevier, Amsterdam.

4. Brierley, G. P (1976) Mol. Cell. Biochem. 10, $41-62$.

5. Brierley, G. P., Jurkowitz, M., AND JunG, D. W. (1978) Arch. Biochem. Biophys. 190, 181-192.

6. Wehrle, J. P., Jurkowitz, M., Scott, K. M., AND BRIERLey, G. P. (1976) Arch. Biochem. Biophys. 174, 312-323.

7. Douglas, M. G., and Cockrell, R. S. (1974) J. Biol. Chem. 249, 5464-5471.

8. Brierley, G. P., AND STONeR, C. D. (1970) Binchemistry 9, 708-713.

9. Scott, K. M., KNight, V. A., Settlemire, C. T., AND BRIERLEY, G. P. Biochemistry 9,714-724.
10. TYLER, D. D. (1969) Biochem. J. 111, 665-678.

11. Stoner, C. D., and Sirak, H. D. (1969) J. Coll. Biol. 43, 521-538.

12. Chavez, E., Jung, D. W., and Brierley, G. P. (1977) Arch. Biochem. Biophys. 183, 460-470.

13. Jung, D. W., ShI, G., AND BRIERLEY, G. P. (1980) J. Biol. Chem. 255, 408-412.

14. Gauthier, L., AND Diwan, J. J. (1979) Biochem. Biophys. Res. Commun. 87, 1072-1079.

15. Azzone, G. F., Massari, S., and Pozzan, T. (1976) Biochim. Biophys. Acta 423, 27-41.

16. Azzi, A., AND AZZone, G. F. (1967) Biochim. Biophys. Acta 131, 468-478.

17. Packer, L., Utsumi, K., And Mustafa, M. G. (1966) Arch. Biochem. Biophys. 117, 381-393.

18. Weinberg, J. M., Simmons, C. F., and Humes, H. D. (1980) Res. Commun. Chem. Pathol. Pharmacol. 27, 521-532.

19. Veloso, D., Guynn, R. W., Oskarsson, M., AND VeECH, R. L. (1973) J. Biol. Chem. 13, 4811-4819.

20. BAR, R. S., Wilson, H. E., AND MazzaferRI, E. L. (1975) Ann. Int. Med. 82, 646-649.

21. Brinkfr, K., Cronin, R., Butger, R., SouthERN, P., AND HENRICH, W. (1980) Clin. Res. 27, $746 \mathrm{~A}$. 